\title{
Cultura de embrião e indução de brotos in vitro para micropropagação do pinhão-manso
}

\author{
Leandro Cesar Lopes(1), Isaac Stringueta Machado(1), Elaine Cristina Magoga( ${ }^{(1)}$, Juliana Granito de Andrade ${ }^{(1)}$, \\ Henrique Curi Penna ${ }^{(1)}$ e Lucas Eduardo Fischer Moraes ${ }^{(1)}$
}

\begin{abstract}
(1)Universidade Estadual Paulista, Faculdade de Ciências Agronômicas, Caixa Postal 237, CEP 18610-307 Botucatu, SP. E-mail: Iclopesagro@gmail.com, isaac@fca.unesp.br, elainemagoga@yahoo.com.br, hinoro_x3@hotmail.com, riquecpenna@hotmail.com, lefmoraes@fca.unesp.br
\end{abstract}

\begin{abstract}
Resumo - O objetivo deste trabalho foi otimizar o cultivo e desenvolvimento de embriões, bem como avaliar a indução da micropropagação do pinhão-manso (Jatropha curcas) in vitro. Na primeira etapa, foi avaliada a influência da sacarose (concentrações $0,15,30$ e $60 \mathrm{~g} \mathrm{~L}^{-1}$ ) no desenvolvimento de embriões em meio basal MS. Das plântulas geradas no cultivo de embriões, foram excisadas microestacas e colocadas em meio MS suplementado com os reguladores vegetais 6-benziladenina (BA), 6-benzilaminopurina (BAP), cinetina (6-furfuriladenina) (KIN) e ácido 4-(3-indolil) butírico (AIB), nas concentrações 0,5, 1,0, 2,0 e 3,0 mg L-1. Os resultados evidenciaram que a faixa de 15 a $30 \mathrm{~g} \mathrm{~L}^{-1}$ de suplementação exógena da sacarose promove o melhor alongamento da parte aérea das plantas; a rizogênese, contudo, é mais vigorosa na faixa de 30 a $60 \mathrm{~g} \mathrm{~L}^{-1}$, em que ocorre aumento significativo do número de raízes. Na fase de micropropagação, o BAP à concentração de 2,0 $\mathrm{mg} \mathrm{L}^{-1}$ induz maior número de brotações, enquanto a $\mathrm{KIN}(1,0$ e 2,0 mg L-1) promove maior número de folhas. Ocorre calogênese na base das brotações, mais significativa na suplementação com 2,0 mg L $\mathrm{m}^{-1}$ de 6-BAP. A melhor concentração de sacarose, quanto ao vigor vegetal e rapidez na obtenção de explantes, é de $30 \mathrm{~g} \mathrm{~L}^{-1}$. Na micropropagação, os melhores resultados da organogênese direta de brotações ocorrem à concentração de $2,0 \mathrm{mg} \mathrm{L}^{-1}$ de BAP.
\end{abstract}

Termos para indexação: Jatropha curcas, auxinas, citocininas, germinação in vitro, organogênese, sacarose.

\section{Embryo culture and in vitro induction of shoots for micropropagation of physic nut}

\begin{abstract}
The objective of this work was to optimize the cultivation and embryo development, as well as to evaluate in vitro micropropagation induction of physic nut (Jatropha curcas). In the initial stage, the influence of sucrose (concentrations of $0,15,30$ and $60 \mathrm{~g} \mathrm{~L}^{-1}$ ) on the development of embryos in basal MS medium was evaluated. From the seedlings generated in the embryo culture, microcuttings were excised and inoculated on MS medium supplemented with the plant regulators 6-benzyladenine (BA), 6-benzylaminopurine (BAP), kinetin (6-furfuryladenine) (KIN) and 4-(3-indolyl) butyric acid (IBA), in the concentrations of 0.5, 1.0, 2.0 and $3.0 \mathrm{mg} \mathrm{L}^{-1}$. The results showed that the range of 15 to $30 \mathrm{~g} \mathrm{~L}^{-1}$ of exogenous supplementation with sucrose promotes the best shoot elongation of plants; however, rhizogenesis is more vigorous in the range from 30 to $60 \mathrm{~g} \mathrm{~L}^{-1}$, in which a significant increase of the number of roots occurs. In the micropropagation phase, BAP at $2.0 \mathrm{mg} \mathrm{L}^{-1}$ concentration induces a higher number of shoots, while $\mathrm{KIN}\left(1.0\right.$ and $\left.2.0 \mathrm{mg} \mathrm{L}^{-1}\right)$ promotes a higher number of leaves. Callogenesis occurs on the shoot base, being more significant when supplemented with $2.0 \mathrm{mg} \mathrm{L}^{-1}$ of 6-BAP. The best sucrose concentration, for plant vigor and speed in obtaining explants, is $30 \mathrm{~g} \mathrm{~L}^{-1}$. In micropropagation, the best results for direct shoot organogenesis occur at $2.0 \mathrm{mg} \mathrm{L}^{-1} \mathrm{BAP}$ concentration.
\end{abstract}

Index terms: Jatropha curcas, auxins, cytokinins, in vitro germination, organogenesis, sucrose.

\section{Introdução}

O pinhão-manso (Jatropha curcas L.) é uma espécie perene, resistente à seca e a solos de baixa fertilidade, nativa da América tropical (Graf, 1992). Apresenta grande potencial econômico, pois suas sementes contêm cerca de $40-50 \%$ de óleo rico em hidrocarbonetos reduzidos, que podem ser convertidos em compostos similares aos derivados do petróleo, como o biodiesel; e, ainda, apresentam propriedades interessantes para a indústria de fármacos e tintas (Arruda et al., 2004). 
Ocorre atualmente um crescente interesse no plantio do pinhão-manso. No entanto, ainda são incipientes os esforços de melhoramento da espécie, entre os quais pode-se destacar o trabalho de Laviola et al. (2012), em que esses autores concluem que tais esforços devem ser inicialmente usados para se identificar árvores de elevado diâmetro de caule, elevado número de ramos e volume de copa, para aumentar as chances de se encontrar árvores excepcionalmente produtivas. Também, Bhering et al. (2012), com o objetivo de estimar ganho genético no melhoramento do pinhão-manso, estudaram diferentes índices de seleção e a melhor estratégia de seleção para a espécie, por meio da avaliação de parâmetros como produtividade de fruto e de semente, anatomia de caule e copa, juvenilidade e inserção da primeira inflorescência, e concluíram que a utilização de índices de seleção é relevante para maximizar os ganhos genéticos e favorecer a melhor distribuição de características desejáveis.

É clara a existência de grandes desafios para que o pinhão-manso possa se tornar viável para o cultivo em larga escala e produção do óleo combustível. Assim, a biotecnologia, aliada a programas de melhoramento, poderá auxiliar no desenvolvimento de cultivares agronômicas e na produção comercial de mudas com alta qualidade fitossanitária em menor período de tempo.

O cultivo de embriões - que ainda necessita de definição de protocolo, para elaboração de meio nutritivo - é uma das técnicas biotecnológicas mais promissoras na pesquisa com o pinhão-manso. Seu desenvolvimento requer estudo da relação e balanceamento dos diversos componentes empregados na composição de meios de cultura. Neste sentido, resultados começam a ser divulgados, relativos à composição orgânica como a adição de sacarose ao cultivo de embriões. Nunes et al. (2008) testaram a influência da sacarose no cultivo de embriões de pinhão-manso, em diferentes estádios de maturação, e concluíram que concentrações superiores a $30 \mathrm{~g} \mathrm{~L}^{-1}$, comumente usadas na cultura de tecidos de plantas, maximizam a percentagem de germinação de embriões oriundos de frutos imaturos; os resultados indicaram a faixa de $60 \mathrm{~g} \mathrm{~L}^{-1}$ como ideal para este tipo de procedimento.

A pesquisa da micropropagação da espécie foi conduzida pela multiplicação mediante indução de gemas adventícias, por organogênese direta (sem passar pela fase de calo), a partir de gemas axilares e ápices caulinares. Os resultados poderão contribuir para o estabelecimento, desenvolvimento e multiplicação em larga escala da espécie in vitro.

O objetivo deste trabalho foi otimizar o cultivo e desenvolvimento de embriões, bem como avaliar a indução da micropropagação do pinhão-manso (Jatropha curcas) in vitro.

\section{Material e Métodos}

O trabalho foi conduzido durante o ano de 2011, no Laboratório de Biotecnologia de Plantas, do Departamento de Recursos Naturais, setor Ciências Ambientais, da Faculdade de Ciências Agronômicas, Fazenda Lageado, Universidade Estadual Paulista (Unesp), Campus de Botucatu, Botucatu, SP.

Sementes maduras e oriundas de polinização aberta foram selecionadas em banco de germoplasma, instalado na Fazenda Experimental São Manuel, da mesma faculdade. Em condições laboratoriais, no mesmo dia da coleta em campo, após lavagem com detergente neutro, foram retirados os tegumentos, e realizadas outras lavagens em água corrente com detergente neutro e enxágues com água destilada e deionizada estéril, e as sementes permaneceram imersas por 12 horas. Após este tempo, procedeu-se à desinfecção das sementes com etanol a $70 \%$ por 1 min, seguida de imersão em solução de hipoclorito de sódio a $2 \%$ de cloro ativo e uma gota de Tween 20, durante $20 \mathrm{~min}$; e, em seguida, foram feitas quatro lavagens em água destilada e deionizada estéril, seguidas de imersão nesta última água.

Em câmara de fluxo laminar, em condições assépticas, foram extraídos 100 embriões que foram, em seguida, imersos (30 min) e manipulados em soluções de ácido ascórbico $\left(0,5 \mathrm{mg} \mathrm{L}^{-1}\right)$ e polivinilpirrolidona $\left(5 \mathrm{~g} \mathrm{~L}^{-1}\right)$ e colocados em meio indutor do desenvolvimento do embrião.

O desenvolvimento de embriões foi pesquisado em delineamento experimental inteiramente casualizado, constituído de quatro tratamentos do meio Murashige-Skoog (MS) com 0, 15, 30 e $60 \mathrm{~g} \mathrm{~L}^{-1} \mathrm{de}$ sacarose. $\mathrm{O} \mathrm{pH}$ do meio foi aferido em 5,8, antes da autoclavagem a $120^{\circ} \mathrm{Ce} 1 \mathrm{~atm}$, por $20 \mathrm{~min}$, e a gelificação foi obtida com $8 \mathrm{~g} \mathrm{~L}^{-1}$ de ágar. Cada tratamento foi constituído de oito repetições, e cada repetição por um explante/tubo de ensaio de 15/2 cm (altura/diâmetro), 
com $20 \mathrm{~mL}$ de meio. Os frascos foram dispostos em sala de crescimento, sem luz nas primeiras 48 horas e, a seguir, com fotoperíodo de 16 horas de luz por 8 horas de escuro, com intensidade luminosa de 2.000 lux e temperatura ambiente de $25^{\circ} \mathrm{C}$.

Os resultados foram obtidos aos 20 dias de cultivo e monitorados por meio das taxas de desenvolvimento da plântula inteira, em cada tratamento. Plântulas inteiras, observadas nos diferentes tratamentos, foram coletadas e fotografadas, e suas partes aéreas foram separadas dos sistemas radiculares, tendo-se obtido os seguintes parâmetros fisiológicos: massa de matéria fresca (MF) e de matéria seca (MSE), altura das partes aéreas $(\mathrm{H})$, número de raízes (NR), comprimento das raízes (CR). A MSE foi obtida pela desidratação da $\mathrm{MF}$ - em estufa a $40^{\circ} \mathrm{C}$, até obtenção de massa constante -, ambas obtidas em miligramas em balança de precisão.

Para a etapa posterior, a micropropagação de plântulas com 20 dias e desenvolvidas a partir dos embriões, foram excisados ápices caulinares e microestacas que continham gemas axilares. Após a retirada das folhas, os explantes foram colocados em meio nutritivo basal MS, suplementado com as seguintes concentrações de reguladores vegetais (BA, 6-benziladenina; BAP, 6-benzilaminopurina; KIN, cinetina 6-furfuriladenina; e AIB, ácido 4-(3-indolil) butírico): T1, 0,5 $\mathrm{mg} \mathrm{L}^{-1}$ de BA; T2, 1,0 $\mathrm{mg} \mathrm{L}^{-1}$ de BA; T3, 2,0 mg L-1 de BA; T4, 3,0 $\mathrm{mg} \mathrm{L}^{-1}$ de BA; T5, 0,5 $\mathrm{mg} \mathrm{L}^{-1}$ de BAP; T6, 1,0 $\mathrm{mg} \mathrm{L}^{-1}$ de BAP; T7, 2,0 $\mathrm{mg} \mathrm{L}^{-1}$ de BAP; T8, 3,0 $\mathrm{mg} \mathrm{L}^{-1}$ de BAP; T9, 0,5 mg L $\mathrm{mg}^{-1}$ KIN; T10, 1,0 $\mathrm{mg} \mathrm{L}^{-1}$ de KIN; T11, e 2,0 $\mathrm{mg} \mathrm{L}^{-1}$ de KIN; e T12, 3,0 $\mathrm{mg} \mathrm{L}^{-1}$ de KIN. A todos os tratamentos foi adicionado $0,5 \mathrm{mg} \mathrm{L}^{-1}$ de AIB.

Os balanceamentos assim propostos foram comparados com meio basal, sem a adição de reguladores vegetais (T0). Foram oito repetições por tratamento, e cada repetição foi constituída por um explante por tubo de ensaio de $15 / 2 \mathrm{~cm}$ altura/ diâmetro, que continha $20 \mathrm{~mL}$ do meio específico. Os frascos foram dispostos em sala de crescimento, em fotoperíodo de 16 horas de luz por 8 horas de escuro, à intensidade luminosa de 2.000 lux e temperatura ambiente de $25^{\circ} \mathrm{C}$.

A micropropagação pela organogênese direta in vitro foi avaliada ao final de 70 dias, pelas taxas de brotação da parte aérea das plantas, para obtenção da frequência do número de brotos dentro do período. Ao final da experimentação, foram obtidos os valores de massa de matéria fresca (MF), massa de matéria seca (MSE) e número de folhas das brotações regeneradas.

$\mathrm{O}$ delineamento experimental inteiramente casualizado foi utilizado, e os resultados da primeira etapa (MF, MSE, H, NR,e CR), assim como os valores em frequência, MF, MSE e NF, das brotações micropropagadas na segunda etapa, foram transformados $(\sqrt{x}=5)$ e comparados por análise de variância, e as médias foram comparadas pelo teste de Tukey, a 5\% de probabilidade, pelo programa ASSISTAT (Silva, 2011).

\section{Resultados e Discussão}

A germinação ocorreu em 100\% dos embriões empregados, que apresentavam, em sua totalidade, cotilédones já diferenciados na semente madura. Foram produzidos tecidos clorofilados na primeira semana e folhas verdadeiras aos 12 dias de cultivo. Não ocorreram diferenças significativas nas médias MF e MSE a $5 \%$ de probabilidade, o que evidencia que a germinação e a produção de biomassa pelas plântulas desenvolvidas independem da presença da sacarose no meio de cultura, pelo menos até o vigésimo dia de experimentação. A Tabela 1 apresenta os resultados encontrados aos 20 dias de estabelecimento in vitro dos embriões.

Diferentemente do encontrado na presente pesquisa, Yamada \& Sato (1978) relataram ser essencial a presença da sacarose no crescimento das culturas in vitro, mas o seu excesso pode ser prejudicial, pelo efeito inibitório na síntese de clorofila, que reduz a capacidade fotossintética dos tecidos. No desenvolvimento de

Tabela 1. Valores médios de massa de matéria fresca (MF), massa de matéria seca (MSE), altura $(\mathrm{H})$, número de raízes (NR) e comprimento das raízes (CR) de pinhão-manso (Jatropha curcas), a diferentes concentrações de sacarose $^{(1)}$.

\begin{tabular}{lccccc}
\hline $\begin{array}{l}\text { Concentração de } \\
\text { sacarose }\left(\mathrm{g} \mathrm{L}^{-1}\right)\end{array}$ & $\begin{array}{c}\text { MF } \\
(\mathrm{mg})\end{array}$ & $\begin{array}{c}\text { MSE } \\
(\mathrm{mg})\end{array}$ & $\begin{array}{c}\mathrm{H} \\
(\mathrm{cm})\end{array}$ & NR & $\begin{array}{c}\text { CR } \\
(\mathrm{cm})\end{array}$ \\
\hline 0 & $206,12 \mathrm{a}$ & $16,10 \mathrm{a}$ & $1,37 \mathrm{~b}$ & $1,75 \mathrm{~b}$ & $0,42 \mathrm{a}$ \\
15 & $277,19 \mathrm{a}$ & $24,55 \mathrm{a}$ & $2,65 \mathrm{a}$ & $3,50 \mathrm{ab}$ & $0,58 \mathrm{a}$ \\
30 & $262,67 \mathrm{a}$ & $24,55 \mathrm{a}$ & $2,42 \mathrm{a}$ & $4,75 \mathrm{a}$ & $0,76 \mathrm{a}$ \\
60 & $210,23 \mathrm{a}$ & $27,78 \mathrm{a}$ & $2,10 \mathrm{ab}$ & $4,75 \mathrm{a}$ & $0,87 \mathrm{a}$ \\
\hline DMS & 4,45 & 1,52 & 0,17 & 0,43 & 0,22 \\
CV $(\%)$ & 29,2 & 31,9 & 10,5 & 21,3 & 20,6 \\
\hline
\end{tabular}

${ }^{(1)}$ Médias seguidas por letras minúsculas distintas, nas colunas, diferem entre si, pelo teste de Tukey, a 5\% de probabilidade. Para a realização dos testes estatísticos, os dados passaram pela transformação $\sqrt{\mathrm{x}}=5$. 
plântulas in vitro, Spera (1995) trabalhou com Jatropha podagrica Hook. e verificou que concentrações de sacarose até $30 \mathrm{~g} \mathrm{~L}^{-1}$ foram suficientes para o bom desenvolvimento do material estudado. Os resultados diversos evidenciam a importância da realização de mais estudos da curva de resposta, em função do aumento da concentração de sacarose e outros açúcares não redutores (rafinose, estaquiose, etc.), para o pinhão-manso e outras espécies.

Com relação ao alongamento $(\mathrm{H})$ das plântulas germinadas, os resultados mostraram que a sacarose, a concentrações de 15 e $30 \mathrm{~g} \mathrm{~L}^{-1}$, apresenta maior eficácia neste processo. A ausência de sacarose no meio causou o atraso do crescimento, e o maior nível de sacarose (60 $\left.\mathrm{g} \mathrm{L}^{-1}\right)$ também mostrou efeito inibitório. Este resultado concorda com o de George \& Sherrington (1984), que observaram que o aumento da concentração de sacarose estimulou o alongamento da parte aérea e a formação de raízes em algumas espécies.

$\mathrm{O}$ número de raízes foi significativamente superior nas concentrações de sacarose de 30 a $60 \mathrm{~g} \mathrm{~L}^{-1}$. Os resultados encontrados concordam com os de Collins \& Dixon (1992) que, ao trabalhar com a orquídea Diuris longifolia R. Br., verificaram que a influência do aumento das concentrações - de 20 para $40 \mathrm{~g} \mathrm{~L}^{-1}$ - incrementou as taxas de enraizamento, dobrou o número de plantas enraizadas e melhorou o desenvolvimento destas. No entanto, Damiani \& Schuch (2009) analisaram diferentes concentrações de sacarose $\left(0,15\right.$ e $\left.30 \mathrm{~g} \mathrm{~L}^{-1}\right)$, no crescimento in vitro de plântulas de mirtilo (Vaccinium ashei J.M. Reade), e verificaram que maiores percentagens de enraizamento ocorreram em meio sem a adição de sacarose.

Diferentemente do número, o comprimento das raízes não foi afetado pela presença da sacarose, pois os efeitos dos tratamentos não diferiram a $5 \%$ de probabilidade. Estes resultados discordam daqueles encontrados por Moreira et al. (2007), que verificaram efeito positivo da sacarose no comprimento de raízes de Sophronitis purpurata (Lindl. \& Paxton) C. Berg \& M.W. Chase x Cattleya warneri T. Moore ex Warner, especialmente às concentrações de 15 e $20 \mathrm{~g} \mathrm{~L}^{-1}$ de sacarose.

Na micropropagação pela organogênese direta in vitro, ocorreu efeito significativo dos tratamentos para as variáveis pesquisadas (Tabela 2), aos 70 dias de inoculação dos explantes obtidos na fase de cultivo e desenvolvimento de embriões.
Marino \& Bertazza (1990) descrevem que, entre as citocininas, a BA é a mais empregada no cultivo de tecidos, pois, em geral, induz maiores taxas de proliferação do que outras, como a zeatina ou cinetina. No entanto, para o pinhão-manso, os resultados mostraram que o número de brotações e diferenciação das gemas adventícias ocorreram em níveis inferiores no meio acrescido de 6-benziladenina, em comparação aos outros reguladores vegetais testados, tendo-se obtido apenas um broto por repetição, como ocorreu no tratamento controle.

A análise dos resultados mostrou que as citocininas BAP e KIN proporcionaram os melhores resultados na multiplicação de brotações (NB), e a concentração de 2,0 $\mathrm{mg} \mathrm{L}^{-1}$ de BAP (T7) evidenciou superioridade em relação aos demais tratamentos. Os níveis de BAP atuam diferentemente segundo a espécie vegetal, como mostrado por Araujo et al. (2006), em estudo sobre propagação in vitro de híbridos de orquídeas, em que encontraram maior brotação em meio MS suplementado com 4,0 $\mathrm{mg} \mathrm{L}^{-1}$ de BAP. Ao trabalhar com porta-enxertos híbridos de Prunus domestica L. $\mathrm{x}$ Prunus persica (L.) Batsch, Marino (1982) concluiu que a concentração de $1,0 \mathrm{mg} \mathrm{L}^{-1}$ de BAP promoveu

Tabela 2. Valores médios do número de brotos (NB), número de folhas (NF), massa de matéria fresca dos brotos (MFB), massa de matéria seca dos brotos (MSB) e massa de matéria fresca dos calos (MFC) de pinhão-manso (Jatropha curcas) $^{(1)}$.

\begin{tabular}{llllcc}
\hline Tratamento & NB & NF & MFB $(\mathrm{mg})$ & MSB $(\mathrm{mg})$ & MFC (g) \\
\hline T0 & $1,00 \mathrm{c}$ & $1,62 \mathrm{~cd}$ & $162,56 \mathrm{bc}$ & $12,85 \mathrm{c}$ & $-(2)$ \\
T1 & $0,75 \mathrm{c}$ & $1,37 \mathrm{~d}$ & $122,49 \mathrm{c}$ & $8,26 \mathrm{c}$ & - \\
T2 & $1,12 \mathrm{c}$ & $3,00 \mathrm{~cd}$ & $174,98 \mathrm{bc}$ & $17,63 \mathrm{bc}$ & - \\
T3 & $1,00 \mathrm{c}$ & $2,62 \mathrm{~cd}$ & $168,86 \mathrm{bc}$ & $15,45 \mathrm{bc}$ & - \\
T4 & $1,12 \mathrm{c}$ & $2,50 \mathrm{~cd}$ & $140,44 \mathrm{c}$ & $15,05 \mathrm{bc}$ & - \\
T5 & $1,87 \mathrm{bc}$ & $4,00 \mathrm{bcd}$ & $259,71 \mathrm{abc}$ & $22,13 \mathrm{abc}$ & $0,54 \mathrm{~d}$ \\
T6 & $2,25 \mathrm{bc}$ & $3,50 \mathrm{~cd}$ & $356,55 \mathrm{abc}$ & $20,41 \mathrm{abc}$ & $2,58 \mathrm{bc}$ \\
T7 & $3,87 \mathrm{a}$ & $5,50 \mathrm{bc}$ & $498,40 \mathrm{a}$ & $31,06 \mathrm{ab}$ & $5,55 \mathrm{a}$ \\
T8 & $2,75 \mathrm{ab}$ & $3,75 \mathrm{~d}$ & $365,96 \mathrm{abc}$ & $23,48 \mathrm{abc}$ & $3,41 \mathrm{~b}$ \\
T9 & $1,12 \mathrm{c}$ & $3,00 \mathrm{~cd}$ & $229,95 \mathrm{bc}$ & $17,05 \mathrm{bc}$ & $0,43 \mathrm{~d}$ \\
T10 & $3,00 \mathrm{ab}$ & $10,62 \mathrm{a}$ & $394,73 \mathrm{ab}$ & $35,66 \mathrm{a}$ & $1,39 \mathrm{~cd}$ \\
T11 & $3,37 \mathrm{ab}$ & $7,87 \mathrm{ab}$ & $369,84 \mathrm{abc}$ & $31,36 \mathrm{ab}$ & $0,82 \mathrm{~cd}$ \\
T12 & $2,00 \mathrm{bc}$ & $3,12 \mathrm{~cd}$ & $181,74 \mathrm{bc}$ & $15,53 \mathrm{bc}$ & $0,38 \mathrm{~d}$ \\
\hline DMS & 0,29 & 0,49 & 4,73 & 1,20 & 1,75 \\
CV (\%) & 19,03 & 24,60 & 31,30 & 27,70 & 59,12 \\
\hline
\end{tabular}

${ }^{(1)}$ Médias seguidas por letras distintas, nas colunas, diferem entre si, pelo teste de Tukey, a 5\% de probabilidade. ${ }^{(2)}$ Tratamentos em que os calos foram menos vigorosos e ocorreram com menor frequência; assim, não seria razoável sua análise estatística. Para a realização dos testes estatísticos, os dados passaram pela transformação $\sqrt{\mathrm{X}}=5$. 
as maiores taxas de multiplicação in vitro de brotações adventícias.

Os meios suplementados com cinetina promoveram maiores taxas em brotações adventícias e, entre as concentrações empregadas - 1,0 e $2,0 \mathrm{mg} \mathrm{L}^{-1}$ (T10 e $\mathrm{T} 11$, respectivamente) - , produziram melhores resultados em número de folhas diferenciadas. Os resultados obtidos corroboram os de Taiz \& Zeiger (2004) que observaram que, em folhas isoladas e tratadas com cinetina, ocorre impedimento da ação das proteases e RNA-ses foliares, promotoras da senescência. Em decorrência disto, no tratamento das plantas com este regulador vegetal, foram observados os maiores índices fisiológicos, com maior desenvolvimento, em razão do aumento da área foliar e da massa de matéria seca, em que se destacam as concentrações de 1,0 e $2,0 \mathrm{mg} \mathrm{L}^{-1}$, especialmente no incremento da massa de matéria seca.

Segundo Conceição et al. (2004), a variação na produção de matéria seca está associada, principalmente, à variação na área foliar. À medida que aumenta o índice de área foliar, a absorção de luz e a taxa de produção de matéria seca também aumentam; essas observações são confirmadas pelos resultados obtidos no presente trabalho.

O tratamento com 2,0 $\mathrm{mg} \mathrm{L}^{-1}$ de BAP apresentou maiores valores de massa de matéria fresca e, também, a maior multiplicidade de gemas e brotos adventícios. O observado alinha-se ao descrito por Caldas et al. (1998), que descreveram as diferenças entre as atuações das citocininas, em que o BAP induz alta taxa de multiplicação de brotações em muitos sistemas de micropropagação, enquanto a KIN permite apenas o crescimento normal sem brotações adventícias múltiplas.

Dos quatro reguladores empregados, apenas BAP e KIN (T6 a T12) induziram 100\% de ocorrência da calogênese, na base das brotações adventícias obtidas na micropropagação; o BAP promoveu os maiores valores em massa de matéria fresca de calos (Tabela 2). Estes resultados se alinham aos encontrados por Machado et al. (2009), que trabalharam com indução da calogênese em Ananas erectifolius L.B. Sm., em que o regulador vegetal thidiazuron, que como o BAP pertence ao grupo das citocininas, mostrou-se poderoso indutor da calogênese; este resultado é dissonante do conhecimento clássico de que as auxinas são os principais indutores deste processo (Hinojosa, 2005).
Embora este evento fisiológico seja interessante para estudos posteriores da obtenção de variabilidade somaclonal, nos programas de melhoramento da espécie, e seja bastante comum em explantes in vitro de espécies lenhosas, não é, contudo, considerado favorável na micropropagação, conforme descrito por Bassan et al. (2006). Erig \& Schuch (2005) também relataram que a formação de calos na zona de enraizamento é indesejável, pois pode afetar a qualidade das raízes, principalmente no que se refere à conexão vascular com a planta. Ainda, neste aspecto, Hamann (1998) observou que em espécies consideradas de difícil enraizamento, geralmente há formação de calos precedentes à formação de raízes.

Os calos obtidos na presente pesquisa apresentaramse bastante friáveis, característica favorecida por uma alta relação entre auxina e citocinina ou pela adição de outros aditivos ao meio nutritivo, como os compostos que contêm grupos - $\mathrm{SH}$ (glutationa, etilxantato de sódio e dietilditiocarbamato), ou ainda, misturas complexas (água de coco e suco de batata ou cenoura), citados por Caldas et al. (1998). A liberação de células, a partir de calos friáveis, é mais rápida do que a partir de calos compactos, o que favorece a regeneração de novas plantas e seleção de biótipos variantes nos programas de melhoramento da espécie (Pescador et al., 2000).

\section{Conclusões}

1. Para o cultivo de embriões de pinhão-manso in vitro, a sacarose não afeta a percentagem e biomassa total das plântulas germinadas, e a concentração de $30 \mathrm{~g} \mathrm{~L}^{-1}$ mostrou-se mais eficiente na promoção do alongamento da parte aérea e aumento do número de raízes.

2. A concentração $2,0 \mathrm{mg} \mathrm{L}^{-1}$ de 6-benzilaminopurina promove a indução de maior número de brotações e gemas adventícias por explante micropropagado.

3. A calogênese ocorre, ainda que em meio basal MS isento de reguladores vegetais; contudo, a suplementação exógena de 2,0 $\mathrm{mg} \mathrm{L}^{-1}$ de 6-benzilaminopurina otimiza este processo.

\section{Agradecimentos}

À Fundação de Amparo à Pesquisa do Estado de São Paulo, pelo apoio financeiro. 


\section{Referências}

ARAUJO, A.G. de; PASQUAL, M.; SILVA, B.A. da; VILLA, F.; ROCHA, H.S.; COSTA, F.C. Propagação in vitro de plântulas de orquídea em diferentes meios de cultura e concentrações de citocinina. Plant Cell and Culture Micropropagation, v.2, p.68-73, 2006.

ARRUDA, F.P. de; BELTRÃO, N.E. de M.; ANDRADE, A.P. de; PEREIRA, W.E.; SEVERINO, L.S. Cultivo do pinhão-manso (Jatropha curcas L.) como alternativa para o Semi-Árido nordestino. Revista Brasileira de Oleaginosas e Fibrosas, v.8, p.789-799, 2004.

BASSAN, J.S.; REINIGER, L.R.S.; ROCHA, B.H.G.; SEVERO, C.R.P.; FLÔRES, A.V. Oxidação fenólica, tipo de explante e meios de cultura no estabelecimento in vitro de canafístula (Peltophorum dubium (Spreng.) Taub.). Ciência Florestal, v.16, p.381-390, 2006.

BHERING, L.L.; LAVIOLA, B.G.; SALGADO, C.C.; SANCHEZ, C.F.B.; ROSADO, T.B.; ALVES, A.A. Prediction of genetic gains in physic nut using selection indexes. Pesquisa Agropecuária Brasileira, v.47, p.402-408, 2012.

CALDAS, L.S.; HARIDASAN, P.; FERREIRA, M.E. Meios nutritivos. In: TORRES, A.C.; CALDAS, L.S.; BUSO, J.A. Cultura de tecidos e transformação genética de plantas. Brasília: Embrapa-SPI: Embrapa CNPH, 1998. v.1, p.87-132.

COLLINS, M.T.; DIXON, K.W. Micropropagation of an Australian terrestrial orchid Diuris longifolia R.Br. Australian Journal of Experimental Agriculture, v.32, p.131-135, 1992.

CONCEIÇÃO, M.K. da; LOPES, N.F.; FORTES, G.R. de L. Partição de matéria seca entre órgãos de batata-doce (Ipomoea batatas (L.) Lam.), cultivares Abóbora e Da Costa. Revista Brasileira de Agrociência, v.10, p.313-316, 2004.

DAMIANI, C.R.; SCHUCH, M.W. Enraizamento in vitro de mirtilo em condições fotoautotróficas. Ciência Rural, v.39, p.1012-1017, 2009.

ERIG, A.C.; SCHUCH, M.W. Micropropagação fotoautotrófica e uso da luz natural. Ciência Rural, v.35, p.961-965, 2005.

GEORGE, E.F.; SHERRINGTON, P.D. Plant propagation by tissue culture. Eversley: Exegetics, 1984. 709p.

GRAF, A.B. Hortica. New Jersey: Roehrs Company, 1992. $1078 \mathrm{p}$.

HAMANN, A. Adventitious root formation in cuttings of loblolly pine (Pinus taeda L.): developmental sequence and effects of maturation. Trees, v.12, p.175-180, 1998.
HINOJOSA, G.F. Auxinas em plantas superiores: síntese e propriedades fisiológicas. In: BARRUETO CID, L.P. (Ed.). Hormônios vegetais em plantas superiores. Brasília: Embrapa Recursos Genéticos e Biotecnologia, 2005. p.15-57.

LAVIOLA, B.G.; ALVES, A.A.; GURGEL, F.L.; ROSADO, T.B.; ROCHA, R.B.; ALBRECHT, J.C. Estimates of genetic parameters for physic nut traits based in the germplasm two years evaluation. Ciência Rural, v.42, p.429-435, 2012.

MACHADO, I.S.; GOMES, A.C.; BERTOZZO, F.; SORIANO, L.; ARCALÁ, L.F.L. de. Indução de calogênese em meristemas de curauá in vitro. Revista Brasileira de Oleaginosas e Fibrosas, v.13, p.83-90, 2009.

MARINO, G. Primi risultati sulla moltiplicazione in vitro di quattro portinnesti, ibridi di susino e pesco, selezionati in Francia. Rivista della Ortoflorofrutticoltura Italiana, v.66, p.369-375, 1982.

MARINO, G.; BERTAZZA, G. Micropropagation of Actinidia deliciosa cvs. Hayvard and Tomuri. Scientia Horticulturae, v.45, p.65-74, 1990.

MOREIRA, B.M.T.; TOMBA, E.C.; ZONETTI, P. da C. Crescimento in vitro de plântulas de orquídea (Laelia purpurata Lind. var. venosa x Cattleya warneri $\mathrm{T}$. Moore alba) sob diferentes concentrações de sacarose e frutose. Revista de Saúde e Biologia, v.2, p.16-21, 2007.

NUNES, C.F.; PASQUAL, M.; SANTOS, D.N. dos; CUSTÓDIO, T.N.; ARAÚJO, A.G. de. Diferentes suplementos no cultivo in vitro de embriões de pinhão-manso. Pesquisa Agropecuária Brasileira, v.43, p.9-14, 2008.

PESCADOR, R.; ARAÚJO, P.S.; MAAS, C.H.; REBELO, R.A.; GIOTTO, C.R.; WENDHAUSEN JUNIOR, R.; LARGURA, G.; TAVARES, L.B.B. Biotecnologia da Piper hispinervium - pimenta longa. Biotecnologia, Ciência e Desenvolvimento, v.3, p.18-23, 2000.

SILVA, F.A.S. ASSISTAT. Versão 7.6. Campina Grande: Universidade Federal de Campina Grande, 2011. Disponível em: $<$ http://www.assistat.com>. Acesso em: 20 jun. 2012.

SPERA, M.R.N. Propagação in vitro de Jatropha podagrica Hook. 1995. 78p. Dissertação (Mestrado) - Universidade Federal de Lavras, Lavras.

TAIZ, L.; ZEIGER, E. Fisiologia vegetal. 3.ed. Porto Alegre: Artmed, 2004. 719p.

YAMADA, Y.; SATO, F. The photoautotrophic culture of chlorophyllous cells. Plant and Cell Physiology, v.19, p.691-699, 1978.

Recebido em 21 de março de 2012 e aprovado em 20 de junho de 2012 